\title{
Perbaikan Saringan dan Sistem Pendingin Mesin Disc Mill Bonggol Jagung
}

\author{
Adhan Efendi \\ Jurusan Pemeliharaan Mesin, Politeknik Negeri Subang \\ E-mail: adhan@polsub.ac.id
}

\begin{abstract}
Abstrak
Mesin Disc mill bonggol jagung milik kelompok ternak Budi Asih di Sentra Peternakan Rakyat (SPR) Cinagarabogo merupakan mesin yang digunakan untuk mengolah sisa hasil pertanian menjadi pakanternak. Mesin disc mill ini mengalami kerusakan pada bagian sistem pendingin dan saringannya. Untuk membantu proses perbaikan mesin disc mill penulis meneliti dan memperbaiki mesin disc mill tersebut dansetelahnya didokumentasikan. Tujuannya agar penyediaan pakan ternak di SPR Cinagarabogo tidak mengalami kekurangan serta meringankan dalam pekerjaan.Metode pengambilan data dilakukan melalui observasi dan dokumentasi kemudian data diolah secara deskriptif kualitatif. Tahapan-tahapan penelitian yaitu: melakukan pertemuan dengan kepala SPR, melakukan identifikasi kerusakan, menyiapkan alat dan bahan, melakukan proses perbaikan. Hasil penelitian menunjukan bahwa: Alat dan bahan yang digunakan dalam proses perbaikan mesin disc mill adalah tool box lengkap (kunci ring dan pas), WD-40, palu, tang, obeng min dan plus, las listrik, gurinda; langkah-langkah perbaikan sistem pendingin pada motor diesel, mesin disc mill adalah membuka pengunci pada saringan udara kering, membersihkan saringan udara kering dan rumah saringan udara kering, mengganti saringan udara kering, memasang kembali saringan udara kering, serta membersihkan area sistem pendingin; Langkah-langkah perbaikan saringan mesin disc mill adalah melepaskan saringan pada rumah pisau pemotong, membuka baut pada rumah saringan, memotong bagian saringan yang rusak, menyiapkan plat untuk memperbaiki saringan, pengelasan saringan, mengunci baut pada rumah saringan, pasangkan kembali sarian ke rumah pisau pemotong. Hasil dari perbaikan ini adalah suhu mesin menurun dan stabil, hasil gilingan menjadi lebih halus dan bagus, serta mesin terlihat lebih bersih dan terawat.
\end{abstract}

Kata Kunci: Disc Mill, Pendingin, Perbaikan Saringan

\section{Abstract}

The Corn Mill Disc Mill machine owned by the Budi Asih livestock group at the Cinagarabogo People's Animal Husbandry Center (SPR) is a machine used to process agricultural residues into animal feed. This disc mill machine suffered damage to the cooling system and filter. To help the process of repairing the disc mill machine, the writer examined and repaired the disc mill machine and documented thereafter. The goal is that the supply of fodder in the Cinagarabogo SPR does not experience shortages and alleviates work.The method of collecting data is done through observation and documentation then the data is processed in a descriptive qualitative manner. The stages of the research are: meeting with the SPR head, identifying the damage, preparing tools and materials, carrying out the repair process.The results showed that: Tools and materials used in the process of repairing the disc mill machine were complete tool boxes (ring and fitting keys), WD-40, hammers, pliers, min and plus screwdrivers, electric welding, gurinda; Steps to improve the cooling system on diesel engines, disc mill 
machines are to unlock the dry air filter, clean the dry air filter and dry air filter house, replace the dry air filter, replace the dry air filter, and clean the cooling system area;. The steps for repairing the disc mill sieve machine are removing the filter in the cutter knife housing, opening the bolt in the filter housing, cutting the damaged filter section, preparing the plate to repair the filter, welding the filter, locking the bolt in the filter housing, reattaching the filter to knife cutter house. The result of this improvement is that the engine temperature decreases and is stable, the grind becomes smoother and better, and the engine looks cleaner and better maintained.

Keywords: Disc Mill, Cooling, Filter Repair

\section{PENDAHULUAN}

Ternak sapi khususnya sapi potong, merupakan salah satu sumber daya penghasil bahan makanan berupa daging yang memiliki nilai ekonomi yang tinggi, dan penting artinya bagi masyarakat. Seiring hal tersebut peternakan sapi memiliki peluang yang cukup besar dengan semakin sadarnya masyarakat akan kebutuhan gizi yang perlu segera dipenuhi.

Kabupaten Subang menjadi proyek rintisan kawasan peternakan sapi potong, selain sudah bisa memenuhi kebutuhan sendiri, di kabupaten Subang sudah ada dua Sentra Peternakan Rakyat. Populasi sapi potong di Subang terus berkembang setiap tahunnya. Populasi tersebut sudah cukup untuk memenuhi kebutuhan lokal Subang. Namun Subang diharapkan bisa berkontribusi mendukung kebutuhan Jawa Barat dan Nasional yang sedang diupayakan, termasuk adanya pilot projek kawasan peternakan sapi potong.

Subang diharapkan menjadi Kabupaten penunjang daging sapi Nasional dan wilayah karena keberadaan dua Sentra Peternakan Rakyat yang di launching awal tahun 2016 sesuai keputusan menteri pertanian [1]. Sentra Peternakan Rakyat Cinagarabogo merupakan salah satu Sentra Peternakan Rakyat yang meliputi Cipunagara dan Cibogo.

Sentra Peternakan Rakyat Cinagarabogo merupakan salah satu penghasil sapi potong. Hal ini banyak bergantung pada sifat hewan dan kemampuan peternak dalam menangani penyediaan pakan. Untuk itu penanganan penyediaan pakan ternak harus dimaksimalkan, dengan maksud untuk menstabilkan pakan yang erat kaitannya dengan kualitas dan kuantitas hasil ternak yang akan dipasarkan. Seiring dengan kemajuan teknologi tepat guna khususnya dibidang peternakan banyak 
ditemukan alat-alat teknologi yang diciptakan untuk mengelola penyediaan pakan. Hal ini disebabkan oleh kurangnya penyediaan pakan dan sumber daya manusia sehingga timbul pemikiran untuk mengelola sisa hasil pertanian menjadi pakan ternak, tujuannya tidak lain untuk meringankan dalam pekerjaan dan penyediaan pakan.

Mesin Disc mill bonggol jagung milik kelompok ternak Budi Asih di Sentra Peternakan Rakyat Cinagarabogo merupakan mesin yang digunakan untuk mengolah sisa hasil pertanian menjadi pakan ternak. Mesin ini dibuat untuk penghancuran bonggol jagung dan setelahnya dicampurkan dengan komponen lain sehingga menjadi pakan ruminansia untuk pakan sapi[2]. Perbaikan sering juga disebut dengan istilah servis ataupun jasa. Pada kegiatan industri, perbaikan dapat diartikan sebagai usaha untuk mengembalikan kondisi mesin yang bermasalah kembali seperti semula[3]. Namun, tindakan perbaikan tidak menuntut mesin harus sama seperti baru, yang diutamakan adalah mesin tersebut dapat berfungsi kembali [4].

Mesin disc mill digunakan oleh industri ternakskala besar maupun kelompok ternak skala kecil, Denganadanyamesinini di kelompok ternak Budi Asihpenyediaanpakanmenjadilebihefektifdanefisiendibandingkansecara manual[5]. Pakan ini dialokasikan bukan hanya untuk kelompok ternak Budi Asih sendiri tetapi juga untuk peternak sapi di kabupaten Subang yang fokus pada pembibitan sapi lokal[6]. Pakan ternak berjenis ruminansia yang terdiri dari limbah jagung, dedak, ampaskecap, mineral, urea dan garam setiap harinya dibuat oleh kelompok ternak budiasih dengan bantuan mesin disc mill bonggol jagung sebagai penghancur bonggol jagung [7].

Hasil wawancara kepada ketua SPR (kang Ocin) mesin Disc mill bonggol jagung ini mengalami kendala, bahwa setiap kali dioperasikan mesin selalu mati, "kira-kira satu jam lebih tapi tidak kurang dari satu jam setengah mesin ini mati saat beroperasi, saya juga tidak tahu kendalanya dimana." Kata Kang Ocinselakuketua SPR CinagarabogoSubang, pada 24 Februari 2019.

Berdasarkan hasil observasi pada tanggal 5 maret 2019,dengan menggunakan metode uji jalan selama 1,5 jam dan pemeriksaan dengan pengecekan menggunakan termometer infrared pada mesin, vibration meter dan 
pengecekanvisual secara keseluruhan. Penulis mendapati kerusakan pada saringan dalam mesin dan suhu kerja yang seharusnya kurang dari $80^{\circ} \mathrm{Cpadamesinini}$ mengalami overheat yaitu mencapai suhu $87-115^{\circ} \mathrm{C}$ karena kurangnya perawatan, maka mesin selalu mengalami kelebihan panas sehingga menyebabkan mesin tidak dapat bekerja secara maksimal (selalu mati). Maka dari itu harus dilakukan medium repair untuk meningkatkan kinerja pada mesin disc mill bonggol jagung sehingga penyediaan pakan ternak tidak mengalami kekurangan. Dengan dilakukannya penelitian ini diharapkan dapat memperbaiki kerusakan yang terjadi pada mesin disc mill milik kelompok ternak budi asih dan memberikan kontribusi dalam proses perawatan mesin disc mill tersebut.

\section{METODE PENELITIAN}

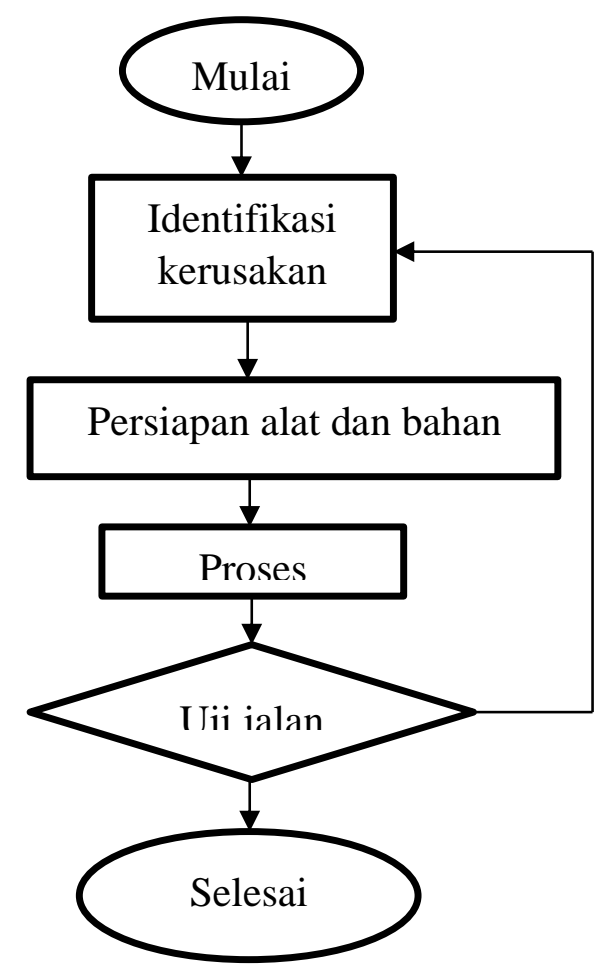

Gambar 2.Alur Penelitian

Identifikasi kerusukan ini adalah untuk mencari kerusakan pada mesin disc mill di kelompok ternak Budi Asih. Ini bertujuan untuk mencari kerusakan pada mesin tersebut sehingga peneliti dapat membuat jadwal untuk segera menyiapkan alat dan bahan untuk perbaikan. Adapun upaya untuk mengidentifikasi kerusakan yaitu:

a. Membuat jadwal pertemuan dengan pihak SPR untuk merencanakan jadwal pengecekan mesin disc mill untuk di identifikasi kerusakannya. 
b. Menyiapkan alat untuk identifikasi kerusakan berupa thermometer imfrared dan vibration meter serta alat ukur tribologi lainnya di kampus Politeknik Negeri Subang.

c. Melakukan identifikasi kerusakan sesuai jadwal yang diberikan oleh pihak SPR.

d. Mengambil data kerusakan dan mendokumentasikan untuk menyiapkan perbaikan mesin disc mill tersebut.

Dari identifikasi keruksakan untuk mempersiapkan bahan penulis mencari bahan ke toko-toko mesin diesel di kota Subang dan juga mencari online di internet. Dan untuk alat yang akan di gunakan penulis dapat menggunakan alat dari bengkel kampus Politeknik Negeri Subang dengan berkordinasi kepada pihak dosen dan teknisi di bengkel kampus Politeknik Negeri Subang.

Proses perbaikan mesin disc mill dilakukan oleh tim dan dibantu oleh pihak teknisi dari SPR, kemudian didokumentasikan dan dideskripsikan secara komulatif. Langkah-langkah yang dilaksanakan dalam rangka perbaikan mesin disc mill yaitu:

a. Studi literatur untuk mencari informasi mengenai mesin disc mill di perpustakaan-perpustakaan terdekat di kota Subang.

b. Berkordinasi dengan pihak SPR dan menyusun jadwal perbaikan yang direncanakan selama 2, 5 bulan untuk melakukan perbaikan mesin.

c. Menyiapkan alat dan bahan yang digunakan selama proses perbaikan mesin.

d. Melakukan langkah-langkah perbaikan mesin.

\section{HASIL DAN PEMBAHASAN}

\section{a. Data Hasil Identifikasi Kerusakan}

Hasil indentifikasi pada observasi awal penulis dan tim menemukan kerusakan diantaranya:

1) Sistem pendingin pada motor dieselmesin disc mill.

Pada observasi awal menggunakan alat thermometer imfrared, tahcometer dan vibration meter peneliti dan tim menemukan indikasi kerusakan pada sistem pendingin.Terlihat dari hasil pengecekan tribologi pada tabel dibawah ini:

Tabel 1 Pengecekan tribologi

\begin{tabular}{|c|c|c|c|}
\hline Menit & Rpm & Suhu & Getaran \\
\hline 15 & 176.2 & 32 & 25.1 \\
\hline 30 & 306.3 & 83.3 & 20.6 \\
\hline
\end{tabular}




\begin{tabular}{|l|l|l|l|}
\hline 45 & 509 & 115 & 20.4 \\
\hline
\end{tabular}

2) Saringan pada mesin disc mill.

Pada observasi awal setelah pengecekan tribologi penulis mendapati kerusakan pada saringan mesin disc mill terlihat dari hasilnya, bonggol jagung tidak hancur merata.

\section{b. Data Alat dan Bahan}

Alat dan bahan yang digunakan dalam perbaikan mesin disc mill yaitu:

1) Alat

Alat yang digunakan dalam perbaikan mesin disc mill diantaranya:

a) Toll box lengkap

b) WD 40

c) Majun

d) Kuas

e) Las listrik

f) Gurinda

g) Palu

h) Tang

i) Obeng min dan plus

2) Bahan

Bahan yang digunakan pada saat perbaikan mesin diantaranya:

a) Solar

b) Filter

c) Water coolant

\section{c. Data Proses Perbaikan}

1) Perbaikan Pergantian Saringan Udara Kering

Saringan udara kering mesin disc mill di kelompok ternak Budi Asih mengalami penyumbatan yang menyebabkan udara yang masuk terhadap mesin menjadi tersendat, karenanya harus ada perbaikan ataupun pergantian pada saringan udara kering tersebut.

Proses perbaikan pergantingan saringan udara kering: 
a) Buka pengnci pada bagian atas saringan udara kering dan pisahkan saringan dengan rumah saringan.

b) Bersihkan rumah saringan menggunakan majun serta solar.

c) Bersihkan saringan menggunakan solar serta majun dan bersihkan menggunakan kompresor, jika sudah tidak layak ganti saringan dengan yang baru.

d) Pasang kembali rumah saringan serta saringan dan kencangkan kembali pengunci menggunakan tang.

2) Perbaikan dan Pembersihan Area Sistem Pendingin

Area sistem pendingin (radiator) pada mesin disc mill mengalami penyumbatan. Kotoran yang menumpuk dan menempel menjadikan aliran udara pada sistem pendingin tersumbat. Maka dari itu pembersihan area pendingin harus dilakukan.

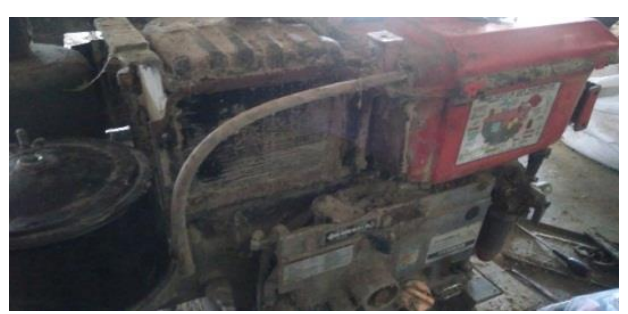

Gambar 8.Sistem pendingin (radiator) kotor

Proses perbaikan dan pembersihan sistem pendingin ialah:

a) Buka mur pada bagian depan sistem pendingin.

b) Lepaskan bagian depan/rumah saringan sistem pendingin.

c) Bersihkan rumah saringan dan saringan dengan majun serta solar.

d) Setelah bersih pasang kembali saringan dan rumah saringan serta kencangkan mur.

\section{d. Uji Kinerja Mesin}

Mesin disc mill yang telah diperbaiki saringan dan sistem pendinginnya kembali dijalankan selama 1, 5 jamnon stop, hasil yang didapatkan adalah mesin dapat bekerja, dan suhu mesin mengalami penurunan[8]. 




Gambar 9. Uji kinerja mesin

Hasil yang didapat dari perbaikan mesin disc mill ini adalah:

1. Saringan dapat digunakan kembali terlihat dari hasilnya komponen yang dihasilkan menjadi kecil merata.

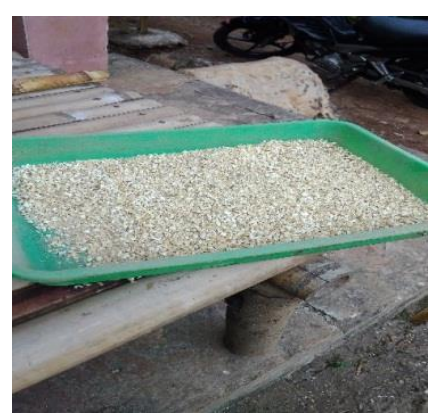

Gambar 10. Hasil penggilingan

2. Suhu mesin mengalami penurunan yang cukup baik, terlihat pada saat pengecekan pada uji kinerja mesin dengan menggunakan alat tribologi yang sama saat observasi awal.
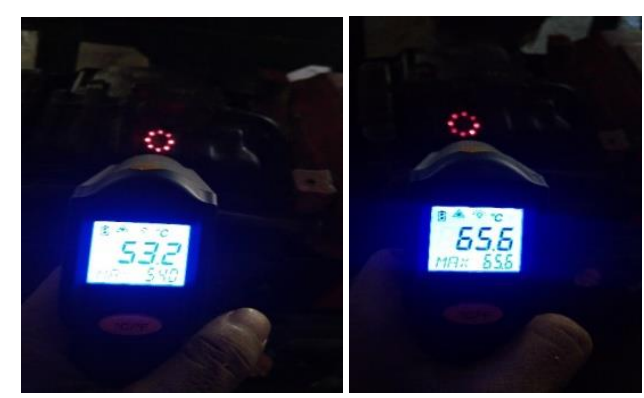

Gambar 11. Hasil Thermometer imfra red

3. Mesin dinyalakan serta menepung dan suhu mesin tetap antara 53 sampai 65 derajat celcius. 
4. Mesin disc mill menjadi lebih bersih setelah perbaikan dan pembersihan. Ditambahkan oleh [9] performa mesinakan lebih baik setelah dilakukan perbaikan.

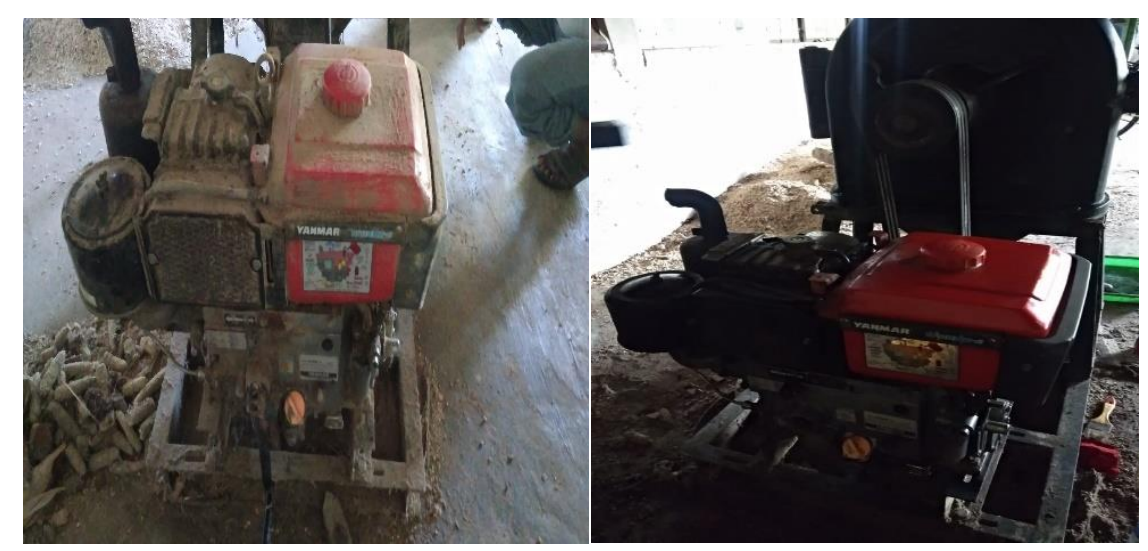

Gambar 12. Perbandingan mesin sesudah diperbaiki

\section{KESIMPULAN}

Kesimpulan yang dapat diambil dari proses perbaikan mesin disc mill adalah:

1. Mesin disc mill di Kelompok Ternak Budi Asih Sentra Peternakan Rakyat Cinagarabogo mengalami kerusakan, maka dari itu perbaikan dan perwatan sangat perlu dilakukan. Kerusakan pada mesin disc mill diantaranya sistem pendingin motor bakar serta saringan mesin.

2. Alat dan bahan yang digunakan dalam proses perbaikan mesin disc mill adalah tool box lengkap (kunci ring dan pas), kuas, majun, WD-40, palu, obeng min dan plus, gurinda, las listrik, saringan udara kering.

3. Proses perbaikan sistem pendingin yaitu, membuka saringan udara kering, mebersihkan dan mengganti saringan udara kering. Proses perbaikan saringan mesin yaitu, melepaskan saringan pada rumah saringan, membuka baut pada saringan, memotong saringan yang rusak, menyiapkan pengganti sisa potongan saringan, pengelasan saringan, memasangkan kembali saringan ke rumah saringan.

4. Hasil dari perbaikan mesin disc mill ialah: saringan dapat kembali digunakan, suhu mesin tidak mengalami overheat (stabil), mesin menjadi bersih dan lebih terawat. 


\section{DAFTAR PUSTAKA}

[1]Adjie, "Pilot Projek Kawasan Peternakan Sapi Potong”, Pikiran Rakyat, Subang, 2016.

[2]Arini, "Prosedur pemeliharaan dan perbaikan dalam ISO 9001", jurnal pemeliharaan teknik mesin, 50-62, 2012.

[3] Adhan\&Roni, "Perbaikan dan pemeliharaan mesin disc mill bongkol jagung", Jurnal Mesin Nusantara, 42-51, 2019.

[4]Zulkarnain, Slamet, dan Hidayat, "Perancangan Mesin Hammer Mill Penghancur Bongkol Jagung dengan Kapasitas 100kg/jam Sebagai Pakan Ternak”. Kudus, Statif, 2014.

[5]Brennan, J.G., Butters, J.R., Cowell, N.D. dan Lilly, A.E.V., "Food Engineering Operations 3 th Ed”., New York, Elsevier Publishing Co., 1990.

[6] Rohman, F., "Karateristik Mesin penepung Disc Tipe FFC 23", Universitas Diponegoro Semarang, 2016.

[7] Oduntan, O. dan Omitoyin,B., "Wear of disc hammer in wet grindingprocesses on groundnut cake for fish feed production”, University of Iba dan Nigeria, 2016.

[8] Assauri, Sofyan, "Manajemen Produksi dan Operasi”. Jakarta, Lembaga Penerbit Fakultas Ekonomi Universitas Indonesia, 2004.

[9] Setyautami, K., "Uji Performance Mesin Penepung Tipe Disc (Disc) untuk Penepungan Juwawut”, Institut Teknologi Bogor, 2008 